\title{
Onde a autogestão acontece: revelações a partir do cotidiano
}

\author{
Cris Fernández Andrada ${ }^{2}$ \\ Instituto de Psicologia da Universidade de São Paulo \\ Verso Cooperativa de Psicologia
}

\begin{abstract}
Este ensaio versa sobre o cotidiano das relações autogestionárias de trabalho, práticas que vêm sendo muito desenvolvidas e incentivadas no contexto atual brasileiro. Para tanto, justifica a escolha do olhar adotado - o cotidiano - e propõe ressignificações do que venham a ser impasses, conflitos e escolhas organizacionais nessas relações de trabalho. Para isso, apresenta e discute a experiência de uma cooperativa de artesanato, com o intuito de reposicionar a importância e o sentido do replanejamento cotidiano do trabalho e das negociações micropolíticas nesse contexto.
\end{abstract}

Palavras-chave: Economia solidária, Cooperativismo, Autogestão, Cotidiano, Conflito, Negociação micropolítica.

Where self-management happens: revelations from everyday practice

This essay focuses on the everyday in self-management work relations, a type of social practice which has been developed and very much encouraged within the current brazilian context. The essay seeks to justify the perspective adopted - the everyday - and proposes the re-signification of that which has been characterized as "impasse", "conflict" and "organizational choices" in this type of work relations. To this end, the experience of an artisans cooperative is presented and discussed, with the objective of re-positioning the importance and meaning of everyday re-planning of work and of the micro-political negotiations characteristic of this context.

Keywords: Social economics, Co-operatives, Self-management, Everyday practice, Conflict, Micro-political negotiation

A cooperativa é o barco da sobrevivência.

Nós juntas vamos remando o barco.

Tem hora que a maré é alta, tem hora que acalma.

Dificuldades tem sempre.

Cooperada da Itacooperarte

\section{O surgimento da Economia Solidária na atualidade brasileira}

Dara conceitualizar o movimento da Economia Solidária, vale recorrer à obra de Paul Singer, quem principalmente concedeu nome e solidez teórica a esse movimento no Brasil. Ele assim o descreve:

A Economia Solidária é outro modo de produção, cujos princípios básicos são a propriedade coletiva ou associada do capital e o direito à liberdade individual. A aplicação desses princípios une todos os que produzem numa única classe de

1 Este texto foi elaborado como trabalho final para a disciplina de pós-graduação "Trabalho, saúde e subjetividade: uma abordagem psicossocial” (IP/USP), ministrada pela Prof. Dra. Leny Sato, no primeiro semestre de 2003.

2 Psicóloga e mestranda em psicologia social. Cooperada da Verso Cooperativa de Psicologia. 
trabalhadores que são possuidores de capital por igual em cada cooperativa ou sociedade econômica (Singer, 2002, p. 10).

A Economia Solidária atual revisita o socialismo utópico - principalmente as obras de Owen, Proudhon, Fourier - e recoloca hoje, na ordem do possível, princípios como a igualdade e a democracia no trabalho, eixos norteadores de inúmeras lutas de trabalhadores nos últimos dois séculos por todo o mundo (Singer, 2002), ainda que descontínuas e pulverizadas. Esse movimento está baseado na união entre a posse e o uso dos meios de produção nas mãos dos sócios-trabalhadores, aliada a uma gestão participativa e democrática dos empreendimentos.

O cooperativismo se viu alavancado ao longo de sua história pelos próprios feitos contraditórios e injustos do modo de produção capitalista. Se em suas origens tinha como contexto a expansão do incipiente capitalismo industrial, gerador do brutal empobrecimento dos artesãos e da exploração ilimitada dos operários (Singer, 2002), hoje ressurge como contraponto aos efeitos do modo de produção capitalista, tal como o desemprego crescente, a superexploração do trabalho, a ampliação de vínculos informais e precários de emprego, entre outras mazelas (Pochmann, 2001).

Diante desse quadro desolador, muitas iniciativas têm sido tomadas por vários setores da sociedade devido à inviabilidade de políticas públicas que, uma vez dirigidas a questões macroestruturais, pudessem conter a avanço dos efeitos dessa crise (Dowbor, 2002). Nesse sentido, a Economia Solidária faz ressurgir fortemente o cooperativismo em vários países, como um dos caminhos possíveis de combate ao desemprego, mas com vistas a ultrapassar esse objetivo, considerando seu poder de contestação de relações subordinadas de trabalho. Muitos vislumbram a possibilidade de construir uma almejada rede de produção e distribuição não-capitalista, ainda que inseridas em uma economia de mercado.

Para Paul Singer, mais que um ressurgimento, trata-se de uma reinvenção, ainda que inspirada nos primeiros movimentos da Escola Associativista do século XIX:

O que distingue este "novo cooperativismo" é a volta aos princípios, o grande valor atribuído à democracia e à igualdade dentro dos empreendimentos, a insistência na autogestão e o repúdio ao assalariamento (Singer, 2002, p. 111).

O incentivo e o financiamento de ações no campo da Economia Solidária têm sido realizados tanto por instituições públicas, quanto por organizações não-governamentais, principalmente nos últimos dez anos. Tais ações são forjadas tanto no cerne de instituições político-partidárias, como também religiosas, sindicais e universitárias ${ }^{3}$, envolvendo um número crescente de trabalhadores ${ }^{4}$.

A Economia Solidária encontra-se na atualidade em franco processo de desenvolvimento, caracterizado por uma dinâmica própria dos movimentos de resistência. Para sobreviver e se desenvolver nesta sociedade, faz-se necessário o confronto dinâmico e permanente de seus princípios socialistas com os vigentes na realidade econômica atual. Embora saibamos que a Economia Solidária surge das injustiças do capitalismo e se orienta de

\footnotetext{
3 Como exemplos desse movimento ressaltam-se os trabalhos da ADS (Agência de Desenvolvimento Solidário ligada à Central Única dos Trabalhadores), da ANTEAG (Associação Nacional de Trabalhadores de Empresas de Autogestão e de Participação Acionária), da UNISOL (União e Solidariedade das Cooperativas do Estado de São Paulo ligada ao Sindicato dos Metalúrgicos do ABC Paulista), entre tantas outras. Merecem destaque também as Incubadoras Tecnológicas de Cooperativas Populares (ITCP), instituições de extensão universitária (organizadas em uma rede nacional) que têm como principal objetivo a geração de trabalho e renda junto a populações pobres, através da formação de cooperativas autogestionárias. Para saber mais, ver: Guimarães (2000) e Singer (2000).

4 Em obra recente sobre experiências autogestionárias no país, Souza (2000) afirma: "Os empreendimentos relatados nesta obra agregam por volta de 100 mil trabalhadores. Esse conjunto é ínfimo no quadro ocupacional brasileiro, mas está em evidente expansão e é extremamente promissor (...)" (p. 7).
} 
modo a superá-las, é em seu seio que os trabalhadores produzem, comercializam e calculam seus custos e retiradas. Essa situação tende a manter-se por bastante tempo, até que possam transcender o campo das utopias, modos também socialistas de comercialização, de crédito, enfim, que possa existir de modo sólido toda uma viva teia econômica necessária para dar sustentabilidade a esse modo de produção.

É justamente em meio a esses embates constantes que surgem expostas as várias contradições basais com o modo de produção hegemônico vigente e elas certamente acarretam difíceis desafios a serem enfrentados por seus sujeitos cotidianamente. Em relação a isso, deve-se levar em conta um agravante importante: esses trabalhadores nasceram e se desenvolveram para o trabalho sob a égide de uma organização social capitalista, pautada pelo assalariamento, pela subordinação, pela divisão capital-trabalho, pela competitividade, enfim, por uma ordem francamente diferente daquela proposta pela Economia Solidária - a partir da qual, agora, assumiram o desafio de viver e trabalhar, ainda que "lá fora" a situação não tenha passado pelo mesmo processo de reorientação (Verardo, 1999).

Tudo isso inevitavelmente complexifica os desafios vislumbrados acima e, se vistos ainda mais de perto, certamente guardam minúcias igualmente ricas e pungentes. Por outro lado, esse panorama alveja pesquisadores com demandas crescentes por maiores estudos e pesquisas dessa realidade, exigindo olhares cada vez mais apurados para o cotidiano das práticas autogestionárias e para o contexto no qual elas se vêem inseridas.

\section{O olhar sobre o cotidiano}

A proposta deste artigo é olhar e refletir sobre o cotidiano das práticas autogestionárias de trabalho, como meio para alcançar uma melhor compreensão dos fenômenos ali vividos por seus sujeitos, pessoas que tornam real a autogestão, suas características, seus meandros, seus desafios, sempre permeados de particularidades e interstícios capazes de passarem desapercebidos a um olhar mais apressado ou entretido apenas com as determinações e os limites macrossociais.

A escolha do cotidiano como foco apóia-se em uma das perspectivas que surge a partir de um profundo debate travado nas ciências sociais, especialmente na sociologia. José de Souza Martins é um dos autores que elucida claramente essa discussão, desenvolvida entre leituras sociológicas positivistas e as chamadas sociologias fenomenológicas. E é em torno desse embate que estas últimas propõem o estudo do senso comum e da vida cotidiana (Martins, 2000).

Para Martins (2000), "é no pequeno mundo de todos os dias que está também o tempo e o lugar das eficácias das vontades individuais, daquilo que faz a força da sociedade civil, dos movimentos sociais" (p. 57). Essa afirmação nos leva a pensar que é no cotidiano que a vida acontece, que a autogestão acontece, que o mundo se faz. $\mathrm{O}$ que não significa, obviamente, que devamos desconsiderar a importância dos momentos solenes de encontro e de reunião. Todos eles também compõem a malha do cotidiano, de certa forma.

E, uma vez sendo o cotidiano o lugar da eficácia política, temos como derivação aquilo que também nos diz Martins sobre o senso comum. Para o autor, este não seria apenas ferramenta de repetições, tampouco é tido como comum por ser banal, mas por se tratar de conhecimento compartilhado pelos sujeitos de determinada situação social (Martins, 2000).

Michel de Certeau (1996), ao ler Vigiar e Punir, de Foucault, também se perguntava que forças humanas eram essas, capazes de resistir a tamanha dominação e vigilância generalizada. "Se é verdade que por toda parte se estende e se precisa a rede de 'vigilância', 
mais urgente ainda é descobrir como é que uma sociedade inteira não se reduz a ela: que procedimentos populares (também minúsculos e cotidianos) jogam com os mecanismos da disciplina (...)" (p. 41). Assim, através de seus interrogantes, esse autor aponta para a tremenda força das práticas cotidianas de resistência e conformação de determinadas realidades sociais, ainda quando estão sob o jugo de fortíssimos mecanismos assimétricos de determinação, controle e poder.

Certeau (1996) também nos fala dos modos de proceder da criatividade cotidiana, das inúmeras maneiras de fazer que cada pessoa se utiliza para reapropriar-se do espaço social que freqüenta e vive. Esses modos de fazer certamente se fazem presentes nas empresas autogestionárias, muito embora não estejam prescritos ou supostos em seus estatutos sociais ou mesmo nos chamados regimentos internos. Assim como cada pessoa tem seu modo singular de agir, de ler ou de cozinhar, cada trabalhador faz escolhas cotidianas sobre sua maneira de cooperar, terá seu modo peculiar de interpretar uma decisão tomada em assembléia ali, no seu dia-a-dia de trabalho, sem que isso venha necessariamente a acarretar um "desvio de sentido" ou, ainda, uma subversão da ordem democrática autogestionária.

Assim como Certeau, Leny Sato (2001) também aponta para a necessidade de olhar para o cotidiano para compreender os processos organizativos, a partir de uma psicologia social do trabalho, utilizando como referencial a etnometodologia ${ }^{5}$. Para ela, esse referencial "possibilita ver as organizações em ação, ultrapassando os papéis sociais e a estrutura formal, os quais, à luz dessa compreensão, passam a ser abstrações” (Sato, 2001, p. 8). Parte dessa autora também um alerta relevante: todas as interações dadas em contextos de trabalho devem considerar que ali também estão presentes as determinações técnicas, não apenas as sociais.

Uma tese importante levantada por Garfinkel (citado por Sato, 2001) afirma que o cotidiano é também sempre organizado. Essa afirmação corrobora com outra de Certeau (1996), que aponta para a existência de regras, de uma lógica entre as práticas cotidianas e corriqueiras. Afinal, não parece possível qualquer ação humana desprovida de um propósito, de um sentido que, por sua vez, necessariamente advém de uma interpretação que o sujeito faz, momento a momento, de sua realidade e de seus interesses, também sempre presentes.

A noção de interpretação que todo sujeito faz, necessariamente, de sua realidade é fundamental para os estudos do cotidiano, e ela vem sempre acompanhada da idéia de circunstância. Como diz Clegg, "todo membro de uma organização é um ser de palavra, um trabalhador e uma individualidade" (Clegg, 1992, p. 54). Segundo ele, ainda no mesmo texto, as identidades dos membros estariam baseadas em diversos fatores, tais como sexo, etnia, e em fenômenos próprios da sua cultura e de seus estilos de vida. Assim, nenhuma pessoa interpretará o mesmo fenômeno, a mesma reunião, por exemplo, do mesmo modo que o fazem seus colegas, por mais afinados que estejam os seus interesses ou por mais fundos que sejam seus vínculos afetivos. Para cada individualidade sempre haverá também uma gama intangível de interesses, própria da sua experiência pessoal e das circunstâncias ali desenhadas. Já Martins aborda essa questão resgatando um dos pilares da teoria marxista, aquele que fala que "os homens fazem sua própria história, mas não a fazem como querem, e sim sob as circunstâncias que encontram" (Martins, 2000, p. 58).

Para Sato (2001), a noção de circunstância de Garfinkel também é rica para pensar as contradições e as mediações entre cada sujeito e a estrutura social. É ela que traz a novidade, o inusitado, segundo a autora, o que exige das pessoas uma criatividade constante, processos de criação e recriação de modos de manejo das situações e de suas complexidades. Ao analisar esse fenômeno, Martins (2000) refere-se ao caráter de instabilidade permanente

5 Segundo Garfinkel (citado por Sato 2001) “os estudos etnometodológicos analisam as atividades cotidianas como os métodos dos membros que fazem essas mesmas atividades visíveis-racionais-e-reportáveis-para-todos-os-propósitos-práticos, isto é, 'accountable', como organizações de atividades cotidianas corriqueiras” (p. 10). Ver a esse respeito: Garfinkel (1994). 
da vida cotidiana, sujeita aos choques com o novo que cada circunstância carrega, demandando dos sujeitos um estado de atenção e vigília permanente, além de habilidades próprias da ousadia ou do atrevimento.

Segundo Giddens (citado por Sato, 2001), outro importante fenômeno que ocorre no interior das práticas cotidianas é a compreensão do significado das ações e das comunicações dos outros que cada sujeito precisa realizar. Trata-se de uma prática qualificada que, nas palavras de Giddens, "constitui um elemento integrante das capacidades de rotina de atores sociais competentes, e é essa competência que os fazem ser membros ${ }^{6}$. A hermenêutica não é apenas um recurso privilegiado do investigador social profissional, mas é praticada por todos" (Giddens citado por Sato, 2001, p. 11). Leny Sato (2001) ainda nos coloca que ocorrem "contínuos processos interpretativos" que todos nós realizamos cotidianamente.

Com isso, já se pode ter uma primeira impressão da complexidade do universo do cotidiano, desse modo de compreensão da vida do dia-a-dia e do senso comum como "a vida em si". Cabe agora pensar o cotidiano de cooperativas autogestionárias à luz dessa discussão, considerando o leque de desafios enfrentado por seus sujeitos, seja pelas razões macroeconômicas supracitadas, seja pelas outras tantas relacionadas com a inexperiência de administrar coletivamente o próprio trabalho, modo democrático, por quem nunca pensou que poderia um dia fazê-lo.

\section{A autogestão no cotidiano}

Leny Sato $(1998,2002)$, em sua pesquisa de doutorado, estudou e conceituou as condições simbólicas em que ocorre o replanejamento negociado do trabalho em uma empresa de produção capitalista. Nesse trabalho, a autora demonstra que os trabalhadores buscam constantemente melhorar suas condições de trabalho, ainda que em um contexto de forte controle técnico e gerencial. Individual ou coletivamente, eles exercem uma resistência à organização imposta, buscando replanejá-la no cotidiano, processo de negociação que se dá incessantemente, mas não de modo linear e aproblemático, já que opera permeado por diversas ambigüidades.

À luz dessa reflexão, podemos pensar que, seja qual for o tipo de organização do trabalho, ela será inevitavelmente revista, redimensionada, testada e contestada por seus sujeitos no cotidiano. Se em uma empresa heterogerida tais processos são "arrancados à força" pelos operários, como nos diz Leny Sato, é de se esperar que na autogestão isso também se dê, ainda que de outras maneiras.

Embora o replanejamento cotidiano do trabalho autogestionário não se dê sempre nos "porões da fábrica", nos interstícios da organização, as experiências demonstram que tampouco esses processos são assépticos, limpos, sempre certeiros e harmônicos, mesmo considerando que eles partem de discussões e de decisões travadas democraticamente por seus agentes.

A tarefa de pensar e definir coletivamente os modos de se trabalhar não é, definitivamente, simples, ainda que se desenvolva apoiada em princípios democráticos. Recordo neste momento uma fala aflita de uma das cooperadas da Itacooperarte ${ }^{7}$, em um

\footnotetext{
6 Este é outro conceito importante para o estudo do cotidiano, já que informa os limites em que ocorrem as interações em que a compreensão é possível. Ainda conforme Sato (2001), as interações são sempre referentes a um determinado grupo - além de a uma determinada situação - que por sua vez dominam determinada linguagem.

7 Cooperativa de artesanato posteriormente citada e descrita neste texto.
} 
momento de franco conflito pelo qual passava o grupo, debruçado na discussão de como partilhar o dinheiro gerado em uma das feiras de artesanato: "Como é difícil não ter patrão!".

\title{
Conflitos no cotidiano autogestionário
}

A própria concepção de conflito parece exigir revisão por parte dos cooperadores, uma vez que divergências jamais deixarão de existir em seus cotidianos. Porém, elas não serão mais indicativos de tensões entre patrão e empregados, mas sim de dinâmicas cotidianas e democráticas de pessoas com interesses, histórias e opiniões diferentes entre si, ainda mais quando expostas à construção de um projeto que guarda tantos desafios e ambigüidades.

Essas demandas por ressignificações advêm, em grande medida, das diferenças de referenciais, de valores existentes entre ambas realidades - entre trabalhar em uma empresa heterogerida ou autogerida - que acabam encerrando compreensões e modos cotidianos de agir diversos e por vezes contraditórios. Concepções anteriores acerca de trabalho, divisão de tarefas, remuneração, planejamento e coordenação das atividades produtivas, são alguns poucos exemplos de questões que trabalhadores envolvidos com empreendimentos autogestionários vêem-se impelidos a rever em seus novos cotidianos de trabalho (Pedrini, 2000; Holzmann, 2001).

Luigi Verardo, representante da $\mathrm{ANTEAG}^{8}$, trata este tema:

\begin{abstract}
Quase todos os trabalhadores vieram de uma situação anterior, em que trabalhavam numa empresa com característica taylorista-fordista ${ }^{9}$, herdaram aquela cultura, visão fragmentária e parcializada do processo de produção que tanto criticamos. (...) Eu trabalhei antes no movimento sindical e sempre achava que os trabalhadores, em seu aspecto subjetivo, teriam facilidade de assumir a gestão das empresas em que trabalhavam. Essa foi uma das minhas desilusões. É impressionante como o taylorismo e o fordismo "fizeram e fazem a cabeça" dos trabalhadores. Como é difícil, esses trabalhadores assumirem, de fato, a gestão da empresa! (Verardo, 1999, p. 71).
\end{abstract}

Uma das causas sempre levantadas para explicar os conflitos em empresas autogeridas é esta que trata da forte presença da concepção de trabalho capitalista em nossa cultura (Sato \& Esteves, 2002; Pedrini, 2000; Holzmann, 2001). Entretanto, cabe colocar outras questões neste debate. A grosso modo, pode-se dizer que onde há pessoas, há também conflitos, por mais liberdade de expressão ou solidariedade que possa ali existir, ou justamente por isso. Sato e Esteves comentam essa questão: "O conflito é a demonstração de que há possibilidade do debate público das questões que permanentemente acometem o empreendimento. O conflito demonstra que há vida política ativa no grupo" (Sato \& Esteves, 2002, p. 42).

Como em todo processo organizativo, as cooperativas autogestionárias são feitas por pessoas e essas só podem ser assim compreendidas se resguardadas suas subjetividades, suas singularidades. Postas lado a lado, as singularidades aparecem como diferenças de interesses, ora convergentes, ora divergentes. A organização cooperativa de trabalho pressupõe a expressão dessas diferenças e, assim, elas passam a servir a todos se solidarizadas, se disponibilizadas para o coletivo. Mas essa dinâmica pressupõe debates, embates, conflitos. Há todo um processo de destruição e reconstrução no meio do caminho, do momento da emergência de diferenças acerca de uma questão, até a chegada a uma decisão coletiva que

8 Associação Nacional dos Trabalhadores de Empresas de Autogestão e de Participação Acionária. Em 2000, a entidade congregava 103 empreendimentos, totalizando aproximadamente 25 mil trabalhadores.

9 O autor refere-se a uma expressão muito utilizada pela engenharia de produção e, por suas conseqüências, também pela economia e pela sociologia, para nomear as formas de produção dominantes desde o século passado. Ver a esse respeito: Antunes (1999). 
possa ter se servido dessa pluralidade e que, de certa forma, também venha para dar sentido a ela. adverte:

Leny Sato (1999), ao se referir às organizações cooperativas como processos sociais,

[...] por serem processos movidos por pessoas, grande diversidade de interesses estará presente. São interesses subjetivos, sociais, econômicos e políticos. Chamo de interesses aquilo que importa às pessoas (Morgan, 1986). E esses interesses conformam os objetivos e informam a direção e o sentido das práticas.

Em função disso pode-se pensar que esses processos sociais são movidos pelo conflito (pois interesses diferentes e até mesmo contraditórios são colocados frente a frente) e pela harmonia (pois interesses semelhantes e comuns também são compartilhados). Com isso, o motor nuclear dessas interações será o binômio cooperação-confrontação (Sato, 1999, p. 221).

Ao pensar o trabalho autogestionário, cabe ressaltar as considerações de Martins sobre o caráter de instabilidade permanente da vida cotidiana. Analisemos agora alguns processos tipicamente autogestionários, tomando como exemplo a experiência de uma cooperativa de artesanato do município de Itapevi, Grande São Paulo.

\section{A experiência das artesãs de Itapevi}

Passo a relatar e analisar brevemente aqui uma experiência vivida junto a uma cooperativa de artesanato de Itapevi, a Itacooperarte ${ }^{10}$. Essas artesãs, que tanto nos ensinaram sobre a condição feminina, sobre trabalho, sobre vida, enfim, novamente vêm nos auxiliar nesta discussão acerca da autogestão no cotidiano.

Tratava-se de um grupo inicialmente de vinte mulheres que lutou incessantemente durante dois anos para constituir uma organização de trabalho que lhes fizesse sentido, que viesse ao encontro não somente de suas necessidades, o que em si já não seria pouco, mas também que ancorasse parte de seus desejos.

A grande maioria dessas trabalhadoras havia passado pela experiência da migração. Em companhia de suas famílias, saíram de seus estados de origem, na região nordestina, em busca de melhores condições de vida. Bairro novo daquela cidade, Santa Cecília atraiu seus moradores através de anúncios de lotes baratos, mais tarde revelados ilegais. Dificuldades de toda índole encontravam-se ali: esgoto a céu aberto, violência urbana e o temido desemprego. A maioria delas sobrevivia da renda dos maridos, que, por sua vez, não encontravam empregos estáveis. Como eles, algumas delas realizavam trabalhos esporádicos e mal-remunerados, os chamados "bicos". A faixa de oscilação das rendas familiares ilustra em parte a realidade desses trabalhadores e trabalhadoras, em geral, as rendas variavam de um a quatro salários mínimos, ainda considerando que muitos dos filhos também contribuíam economicamente para o sustento de suas casas.

Grande parte do grupo já se conhecia há anos de outras experiências coletivas. Haviam sido companheiras em lutas por melhorias do bairro, em grupos de orações e em outras tantas atividades junto à igreja católica local. Encontravam-se em grupos de culinária, de corte e costura, de mães, de discussões sobre sexualidade feminina. Em meio a tantas

10 Entre os anos de 1999 e 2001, tive a singular oportunidade de acompanhar o processo de formação desta cooperativa como membro da equipe de formadores da ITCP-USP (Incubadora Tecnológica de Cooperativas Populares da USP). A esse respeito, ver Andrada, Esteves e Silva (2001). 
partilhas, acabaram também por compartilhar as dificuldades de sobrevivência, próprias de suas condições de pobreza e de instabilidade. Nesse ímpeto, algumas delas aprenderam a fazer cestaria com jornal (objetos feitos com canudos de papel-jornal trançados e pintados ou envernizados), a partir de um programa de televisão. Com essa atividade econômica em mãos, passaram a realizar as primeiras vendas e, logo em seguida, procuraram a ITCP-USP ${ }^{11}$ para ajudá-las a se constituir como uma cooperativa autogestionária.

Para exemplificar o tema do cotidiano da autogestão, inúmeros recortes poderiam ser feitos, baseados na experiência da Itacooperarte. Os processos de replanejamento cotidiano do trabalho foram sempre ricos e constantes nesse contexto, bem como os conflitos, os impasses, as tomadas de decisão, as tantas escolhas e reescolhas. Freqüentemente um novo fato emergia da realidade mutante, somava-se a outros tantos próprios daquele momento, colocando as artesãs frente a mais um impasse ou conflito. Como conseqüência, elas se viam impelidas à negociação imediata e cotidiana.

Poderia ser o sabor do café que, num só tempo, agradava a umas e desagradava a outras. Isso, que à distância pode soar desimportante, ali assumia múltiplos sentidos, mesclava-se a outras questões do dia-a-dia e, por si só, levava as artesãs a desenvolver estratégias de negociação e de ação micropolítica, aprendizados que certamente poderiam ser considerados em novas situações, inspirando outros processos de replanejamento cotidiano do trabalho.

Outro exemplo era a escala da equipe de pintura da cestaria, que volta e meia retornava como questão problemática, já que havia a exigência de uma atenção permanente para as condições climáticas a fim de não comprometer a qualidade das peças. Assim, a comissão responsável deveria estar de prontidão, observando se havia risco de chuvas, de aumento de umidade ou, ainda, caso contrário, em dias de tempo bom, deveria correr para o ateliê para "adiantar o serviço". A exigência de tamanha sincronicidade - entre o processo de produção e as condições climáticas - para algumas trabalhadoras era exagerada. Para outras, era inevitável e deveria sempre ser cumprida a contento. Localizado o conflito, e mesmo antes disso, muitas tentativas de replanejamento foram engendradas, maneiras diversas de compor a comissão e, inclusive, de proceder com a atividade da pintura.

Pode-sedizer que temas como esses ocorriam justapostos, imbricados, emaranhados. Embora extremamente interessante, trata-se de uma trama por demais complexa para ser transposta e analisada com toda sua riqueza neste artigo. Assim, opta-se aqui por relatar os processos de discussão em torno de dois temas muito trabalhados pelas cooperadas, quais sejam, o cotidiano da produção e a definição do regime de remuneração ou, nas palavras das próprias cooperadas, "a questão do dinheiro".

\section{A produção cotidiana da cestaria: diferenças, conflitos e constantes replanejamentos}

A questão da qualidade das peças produzidas frente às desigualdades de habilidades entre as cooperadas, nas várias etapas do processo produtivo, era outro grande núcleo gerador de negociações micropolíticas e cotidianas.

Quase todas as cooperadas sabiam fazer o canudo de papel-jornal, que servia como fibra no trabalho de cestaria do grupo. Ainda assim, à medida que a cooperativa foi aumentando suas vendas e, conseqüentemente, sua visibilidade, surgia uma preocupação também crescente quanto à qualidade das peças. Muitas defendiam critérios mínimos de qualidade, ainda que não usassem essa expressão. $O$ canudo, por exemplo, a fim de conferir maior firmeza e durabilidade à peça, deveria ser o mais fino e rígido possível. $\mathrm{O}$ trabalho de 
trançado das peças era muito respeitado, nem todas se sentiam aptas para tamanha expressão artística. A pintura também guardava seus segredos e acabou sendo a principal marca do trabalho da cooperativa: os inesquecíveis tons mesclados, matizes que iam e vinham entrelaçados sem começo ou fim.

Se, na prática de enrolar o canudo, já nem todas chegavam à fibra fina e dura, tal desigualdade crescia nos terrenos do trançado e da pintura. As cooperadas falavam muito dessa questão. Diziam que ali na cooperativa as pessoas deveriam se sentir à vontade para fazer e aprender o que quisessem, afinal, não havia patrão. Mas também diziam que o ideal era que todo o grupo soubesse realizar todas as etapas da produção, que todas ganhariam com isso, a produção aumentaria, o rodízio de funções seria mais possível. Importante frisar que comentários como esses nem sempre chegam assim, ordenados, puros. Muitas vezes, surgiam acompanhados de desolação, quando uma delas se via diante de seus canudos frouxos, recusados para o trançado. Ou, ainda, vinham impacientes, preocupados com o sucesso da cooperativa.

Conflitos, bem como diversas estratégias de replanejamento do trabalho, brotavam diariamente. Os primeiros eram evidenciados sob a forma de breves comentários, "indiretas", ou mesmo a partir de um olhar triste ou desgostoso. As estratégias de replanejamento para tentar lidar com o problema eram fartas: ora pequenos grupos se reuniam para treinar a confecção do canudo em torno das colegas mais hábeis no ofício. $\mathrm{O}$ mesmo ocorria com o trançado e a pintura. Ora também ocorriam gestos individuais, na forma de uma bronca ou de uma aula.

Fora do espaço das reuniões, ali mesmo, debruçadas sobre a bancada comum de trabalho, uma idéia surgiu e entusiasmou o grupo: fariam "oficinas de criatividade". Eram reuniões periódicas, aos sábados, para o aprendizado e o aprimoramento das práticas da produção, bem como para o desenvolvimento de novos produtos. O resultado disso foi surpreendente: muitas delas aos poucos ousaram incursões em áreas antes pouco dominadas. Dessas manhãs de sábado começaram a surgir também luminárias, porta-retratos e até pequenos móveis trançados em jornal. Mas esse tema e tantos outros vividos pelo grupo não terminam com finais felizes, coroados pela chegada ao "modo certo de fazer". As desigualdades diminuíram, mas nunca deixaram de existir, nem tampouco os conflitos cessaram em torno das oficinas. Constantemente elas retomavam o assunto, mas já não da mesma forma, já era possível partir de outro ponto.

\section{Outro exemplo: a escolha do regime de remuneração da cooperativa}

A primeira forma de organização do trabalho nesse ponto consistiu em não dividir o fundo comum que possuíam. Advindo das primeiras vendas, ele serviria como capital social e de giro da cooperativa. Entretanto, em função de uma mudança nas circunstâncias - o aumento das vendas de seus produtos -, o grupo decidiu rever a deliberação anterior e iniciar o processo de remuneração.

Reunidas em sua primeira assembléia, as artesãs decidiram, a partir de um rápido consenso, dividir de modo igualitário a renda gerada, algo que lhes parecia casar perfeitamente com a sua história e com suas concepções.

Anteriormente essas decisões eram tomadas durante a execução do trabalho, ou seja, não havia espaços formais de decisão. Saídas do momento de "suspensão da realidade", próprio das reuniões, elas se depararam com os impasses gerados no cotidiano por essa suspensão. Surgiam diferenças de opiniões, conflitos, enfim. Conversas informais no horário de trabalho e outras reuniões vieram posteriormente revelar que nem todas as cooperadas estavam dedicando o mesmo tempo de trabalho para a cooperativa, não porque não desejassem, mas porque outros compromissos as impediam. Algumas delas exerciam trabalhos 
informais, necessários para complementar a renda familiar, outras se deparavam com problemas de saúde ou enfrentavam outras limitações familiares.

Em função disso, as artesãs se sentiram inclinadas a rever a última decisão e propor outra política de remuneração. Elas optaram por fixar um horário comum de trabalho e, para isso, olharam cuidadosamente para seus compromissos familiares, de modo a contemplá-los. Já que a cooperativa existia para servir a seus interesses e não o contrário, deveria haver tempo e espaço para preparar o almoço da família e levar os filhos para a escola, por exemplo. Além disso, pensaram um mecanismo de reposição de eventuais faltas, ocasionadas pelos "bicos" ou por questões de saúde. Essas preocupações e iniciativas demonstram que o grupo buscava contemplar outras esferas da vida, o mundo além-trabalho. Talvez mais do que isso, já que para elas a consagrada divisão tempo de trabalho/tempo de não-trabalho - e suas outras versões, trabalho/lazer/vida pessoal - não parecia gozar do sentido comum atribuído na organização do trabalho capitalista.

Isso feito. Novamente elas se depararam com a inadequação da escolha no dia-a-dia, já que a adoção do horário fixo apenas diminuiu, mas não eliminou por si só, as dedicações desiguais em termos de horas de trabalho. As diferenças permaneciam e, com elas, os conflitos.

Medidas intermediárias foram pensadas e adotadas pelo grupo. As discussões sobre como deveria ser o regime de remuneração não cessavam, tanto nas pautas das reuniões, quanto no cotidiano de trabalho. Cada uma tinha suas hipóteses para explicar o problema e sugestões de como resolvê-lo, mas foi somente em nova reunião que outra decisão a esse respeito se configurou.

As artesãs foram levadas a rever novamente a escolha feita, por força da realidade cotidiana. Decidiram nesse momento adotar o regime de remuneração por horas trabalhadas, o que exigiu delas o estabelecimento de todo um mecanismo de controle das mesmas. A partir daí, novos conflitos e problemas surgiram, algumas de início se recusaram a utilizar um caderno que registrasse os horários de entrada e saída. Uma delas disse a esse respeito: "Eu não quero ter patrão, ter que marcar horário". A semelhança com o temido "livro de ponto" era aversiva, assustadora.

Muitas discussões em todos os âmbitos da cooperativa se deram a partir daí. Nesses debates, pôde-se notar todo um processo de ressignificação das formalizações e dos mecanismos de controle, como o "livro das horas". Eles deveriam vir somente quando necessário, para servir às necessidades do grupo, para tornar viáveis, por exemplo, a implementação de suas escolhas, não mais para coagi-las ou para exigir índices impossíveis de produtividade.

O grupo passou a adotar esse sistema e, formalmente, esaa política de remuneração foi a que prevaleceu. Entretanto, acompanhando a história cotidiana do grupo, foi possível perceber que vários ajustes foram necessários, como a formação de uma comissão que cuidasse dos registros e dos cálculos realizados mensalmente. Além disso, de início surgiram atitudes preocupantes. Notou-se um acréscimo considerável na quantidade de horas trabalhadas, ou mesmo alguns registros de horários que não condiziam com a realidade, mas que seguiam um padrão bastante conhecido: "Entrada 8 h; Saída 18 h", todos os dias. A comissão foi tomada por um grande mal-estar, mas soube manejar a questão de maneira surpreendente, conversando com as pessoas envolvidas, esclarecendo dúvidas e, posteriormente, levando com cuidado o tema para a reunião geral.

Após esse processo, o sistema de remuneração adotado pelas artesãs foi mantido, muito embora sempre houvesse a necessidade de uma revisão constante entre as decisões tomadas, suas implementações e pequenas mudanças da realidade. Essa dinâmica, própria dos 
replanejamentos cotidianos, também pôde ser observada em outras questões da cooperativa, não apenas no tocante à remuneração.

O grupo posteriormente se desfez em um processo de lenta e sofrida agonia. Embora as trabalhadoras se mantivessem unidas, muitas delas tiveram que deixar o grupo pela necessidade imediata de gerar renda suficiente para o seu sustento e o de sua família, já que a cooperativa nunca chegou a atingir níveis de faturamento que possibilitassem isso a todas. Um pequeno grupo ainda lutou por mais tempo, aguerridas na luta pelo "sonho da cooperativa". Entretanto, as dificuldades foram mais fortes: a falta de canais de comercialização, os limites da atividade econômica escolhida, além da ausência de uma política de crédito viável para elas naquele momento impediram que a luta delas pudesse continuar.

\section{Algumas considerações à luz do caso relatado}

Ao analisar a experiência das artesãs da Itacooperarte, emergem questões que poderiam abrir diversas frentes de debate sobre o cotidiano autogestionário. Algumas delas seguem expostas abaixo.

\section{A autogestão no cotidiano: reescolhas e replanejamentos constantes}

A experiência relatada nos possibilita pensar acerca dos inevitáveis processos de revisão das decisões coletivas que ocorrem no seio de todo empreendimento econômico. Em verdade, trata-se de uma dinâmica típica de todo cotidiano, conforme colocado anteriormente, mas que na situação autogestionária, guarda singularidades. Muitos podem pensar que isso ocorre porque não são tomadas as "melhores decisões" ou que elas não se dão "da melhor forma" ou, pior, que isso reflete a inabilidade dos trabalhadores em administrar uma empresa. Está claro que não se tem por objetivo aqui chegar a conclusões gerais e aplicáveis a toda situação autogestionária, mas sim analisar algumas de suas características e dinâmicas.

Segundo Leny Sato (2002), planejar é uma atividade dialógico-discursiva. Ou seja, é um processo micropolítico de negociação em que diferentes pontos de vista e interesses são postos lado a lado, confrontados com argumentos diferentes. E, de fato, assim ocorria na Itacooperarte. Naturalmente, esse processo ocorre quando há o que decidir, ou seja, diante de um impasse que dispara um processo de negociação, como a desigualdade de aptidões diante do processo produtivo ou, ainda, a inadequação do regime de remuneração frente aos desejos e às necessidades do grupo.

Interessante pensar que os conflitos e os impasses podem ser vistos como sinalizadores, como verdadeiras pistas de que há um trabalho de negociação micropolítico a ser feito. A partir daí, em meio a possíveis conflitos, é que se chega às chamadas escolhas organizacionais (Kelly citado por Sato, 2002).

Tais escolhas são as próprias decisões do grupo, que podem ser frutos de negociações ocorridas em espaços formais de decisão (como reuniões e assembléias) ou não, já que elas também se dão informalmente em meio às interações cotidianas (Sato, 2002; Andrada, Esteves \& Silva, 2001), como ilustrou acima o caso das "oficinas de criatividade".

Uma vez considerado o fato de que cada processo de negociação e de escolha organizacional ocorre embasado em uma determinada demanda e em um determinado contexto, compreende-se que, alteradas as circunstâncias, esse processo deva ser refeito, já 
que a decisão anterior pode se apresentar insuficiente ou inadequada a partir de então, conforme bem ilustra o caso da Itacooperarte.

Vale resgatar aqui as palavras de Melucci sobre os processos de negociação: "A negociação se torna, então, uma relação processual, uma tentativa de percorrer juntos, cada um do seu lado, a estrada difícil de reconhecermo-nos unidos e diversos" (Melucci citado por Pedrini, 2000, p. 41).

\section{Necessidades e limites das formalizações de procedimentos na autogestão}

Há ainda outro complicador, se considerarmos que muitas das escolhas organizacionais são realizadas nos espaços formais de decisão. Em si, isso não representa necessariamente um problema; faz-se necessário, de certa forma, que isso ocorra, mas exige cuidados. Esses momentos são inevitavelmente situações de "suspensão do cotidiano" em que cada cooperado precisa fazer um exercício de abstração acerca de como seria tal decisão vivida dia a dia, no tempo e no espaço de trabalho.

Observa-se que em muitas cooperativas, como no caso da Itacooperarte, são tomadas decisões que, no plano abstrato, parecem ótimas, seriam saídas criativas para o problema enfrentado, contemplariam as diferenças existentes e parecem ainda estar embasadas em teses muito consistentes. Porém, posteriormente, revelam-se falhas, às vezes, por motivos intangíveis. Interessante notar que espaços formais de discussão nos liberam para a criação, a abstração, a reflexão livre. São os lugares por excelência para tudo isso, mas suas deliberações vão servir a outro cenário, o do cotidiano, envolto em determinações das mais diversas e inconstantes, conforme vimos anteriormente.

A discussão sobre as formalizações nas práticas autogestionárias se faz presente de modo constante e transversal, tanto nas experiências de cooperados, como nas dos formadores e dos estudiosos da Economia Solidária. Ao que tudo indica, parece se tratar de um dilema, na medida em que surgem delineados consensos aparentemente contraditórios a respeito do tema.

Por um lado, reconhece-se a importância do estabelecimento de procedimentos, de mecanismos de controle e de registro, de distribuição de tarefas, entre tantos outros, como necessários e importantes para a sobrevivência de todo empreendimento econômico. Além disso, eles também são fundamentais para propiciar uma boa dinâmica interna e, conseqüentemente, a participação dos cooperados nas instâncias da cooperativa. É claro que tudo isso estará condicionado ao uso que se fará de tais instrumentos.

Entretanto, teme-se que um excesso de formalização amarre as cooperativas nas tramas da burocracia, o que, paradoxalmente, poderia dificultar o exercício cotidiano da autogestão, correndo-se o risco, com o passar do tempo, de virem a se reproduzir processos capitalistas de gestão e de organização.

A tarefa de constituir e gerir uma empresa autogestionária neste contexto sóciohistórico carrega muitas ambigüidades, como já foi dito. Sabe-se de início e o tempo todo o que não se quer em uma cooperativa autogestionária: hierarquia, subordinação, burocratização alienante, cisão planejamento-execução, competição interna, entre tantas outras marcas das práticas administrativas e gerenciais do modo de produção capitalista.

Entretanto, por mais que haja clareza e consenso acerca dos princípios autogestionários capazes de se contrapor a todo esse arcabouço, não se tem disponíveis de antemão as maneiras de implementá-los, talvez por suas próprias características. Ora, não se trata de reivindicar um "manual de autogestão", pois sabemos, por princípio e coerência, que cada cooperativa autogestionária existe para servir a seus sócios-trabalhadores, que obviamente formam um grupo singular, com necessidades e projetos igualmente únicos. 
Assim sendo, caberá a cada grupo o estabelecimento de regras e princípios de gestão que mais façam sentido a todo seu espectro de singularidades. Porém, o que aparentemente parece claro e simples no âmbito das considerações teóricas, é vivido com muita tensão cotidiana por seus sujeitos, como bem nos mostram as artesãs de Itapevi.

Nas palavras de Dalila Pedrini (2000), em artigo sobre o seu estudo junto à empresa autogestionária Bruscor ${ }^{12}$ :

Em se tratando de analisar uma empresa autogestionária, é necessário reconhecer que a burocracia e o controle têm dimensão dupla e contraditória. Nas empresas mercantis tradicionais o controle é exercido para extrair o máximo de produtividade, está a serviço da exploração e é intrinsecamente distinto do controle coletivo da autogestão. Digamos assim, que pode haver um modo de controle e de burocracia que venha a defender os direitos dos trabalhadores, no caso do controle que os favoreça e da normatização que proteja a autogestão (p. 38-39).

\section{Considerações Finais}

As reflexões aqui traçadas apontam para o caráter fundamental das negociações micropolíticas no cotidiano do trabalho autogestionário, consideração compartilhada com Sato e Esteves (2002). Ainda que estejam livres dos embates em torno da tensão capitaltrabalho e de todas as suas mazelas, os trabalhadores das cooperativas autogestionárias estarão sempre inevitavelmente expostos a outra espécie de conflitos. Conflitos esses que advém de suas próprias singularidades, de suas histórias e interesses pessoais e das circunstâncias mutantes em que vivem. E mais, os mesmos conflitos, por vezes angustiantes e penosos, podem servir como importantes ferramentas em suas lidas diárias para manter viva e sólida essa maneira democrática de viver o trabalho, na medida em que sinalizam as tarefas micropolíticas que pedem negociação e replanejamento, salvaguardando, paradoxalmente, as possibilidades revolucionárias de adaptar o trabalho à suas condições psicossociais de vida, não mais o contrário.

\section{Referências}

Andrada, C., Esteves, E. \& Silva, A. (2001). Psicologia e autogestão: trabalhadoras como sujeitos da construção cotidiana e negociada de uma cooperativa de artesanato. São Paulo. [mímeo]

Antunes, R. (1999). Os sentidos do trabalho. São Paulo: Boitempo.

Certeau, M. (1996). A invenção do cotidiano: artes de fazer. Petrópolis: Vozes.

Clegg, S. (1992). Poder, linguagem e ação nas organizações. In J. F. Chanlat (Org.). O indivíduo na organização: dimensões esquecidas (vol. 2, pp. 37-66). São Paulo: Atlas.

Dowbor, L. (2002). O que acontece com o trabalho? São Paulo: Senac.

Guimarães, G. (2000). Incubadoras Tecnológicas de Cooperativas Populares: contribuição para um modelo alternativo de geração de trabalho e renda. In P. Singer \& A. Souza (Orgs.). A economia solidária no Brasil: a autogestão como resposta ao desemprego (pp. 111-122). São Paulo: Contexto.

12 Ver a esse respeito também: Pedrini (1998). 
Holzmann, L. (2001). Operários sem patrão: gestão cooperativa e dilemas da democracia. São Carlos: UFSCar.

Martins, J. de S. (2000). A sociabilidade do homem simples. São Paulo: Hucitec.

Pedrini, D. M. (1998). Entre laços e nós. Associativismo, autogestão, identidade coletiva: a empresa alternativa de produção socializada de Brusque, SC. Tese de doutorado, Programa de Estudos PósGraduados em Serviço Social, Pontifícia Universidade Católica de São Paulo, São Paulo.

Pedrini, D. M. (2000). Bruscor, uma experiência que aponta caminhos. In P. Singer, \& A. Souza (Orgs.). A economia solidária no Brasil: a autogestão como resposta ao desemprego (pp. 31-48). São Paulo: Contexto.

Pochmann, M. (2001). O emprego na globalização: a nova divisão do trabalho e os caminhos que o Brasil escolheu. São Paulo: Boitempo.

Sato, L. (1999). "Djunta-mon": O processo de construção de organizações cooperativas. Psicologia USP, 2 (10), 221-227.

Sato, L. (2001). Processos organizativos cotidianos e corriqueiros: a abordagem da etnometodologia. Psicologia EO Sociedade, 13 (1), 129-151.

Sato, L. (1998). Astúcia e ambigüidade: as condições simbólicas para o replanejamento negociado do trabalho no chão de fábrica. Tese de doutorado, Instituto de Psicologia, Universidade de São Paulo, São Paulo.

Sato, L. (2002). Prevenção de agravos à saúde do trabalhador: replanejando o trabalho através das negociações cotidianas. Cadernos de Saúde Pública, 18 (5), 1147-1166.

Sato, L. \& Esteves, E. (2002). Autogestão: possibilidades e ambigüidades de um processo organizativo peculiar. São Paulo: ADS/CUT.

Singer, P. \& Souza, A. (2000). A economia solidária no Brasil: a autogestão como resposta ao desemprego. São Paulo: Contexto.

Singer, P. (2002). Introdução à Economia Solidária. São Paulo: Perseu Abramo.

Souza, A. (2000). Um instantâneo da economia solidária no Brasil. In P. Singer \& A. Souza (Orgs.). A economia solidária no Brasil: a autogestão como resposta ao desemprego (pp. 7-10). São Paulo: Contexto.

Verardo, L. (1999). Desemprego e autogestão. Cadernos de Psicologia Social do Trabalho, 2, 68-73.

Endereço para correspondência: andrada@usp.br

Recebido em: 02/12/2004

Envio de pareceres em: 09/05/2005

Aprovado em: 10/06/2005 